\title{
On the relation between expected returns and implied cost of capital
}

\author{
John Hughes · Jing Liu · Jun Liu
}

(C) The Author(s) 2009. This article is published with open access at Springerlink.com

\begin{abstract}
We examine the relation between implied cost of capital and expected returns under an assumption that expected returns are stochastic, a property supported by theory and empirical evidence. We demonstrate that implied cost of capital differs from expected return, on average, by a function encompassing volatilities of, as well as correlation between, expected returns and cash flows, growth in cash flows, and leverage. These results provide alternative explanations for findings from empirical studies employing implied cost of capital on the magnitude of the market risk premium; predictability of future returns; and the relations between cost of capital and a host of firm characteristics, such as growth, leverage, idiosyncratic risk and the firm's information environment.
\end{abstract}

Keywords Expected return - Implied cost of capital ·

Weighted average cost of capital

JEL Classifications $\mathrm{G} 12 \cdot \mathrm{G} 14 \cdot \mathrm{M} 41$

\section{Introduction}

We theoretically analyze the properties of "implied cost of capital," defined as the internal rate of return that equates stock price with the present value of the expected

\footnotetext{
J. Hughes $(\bowtie) \cdot$ J. Liu

University of California Los Angeles, Los Angeles, CA, USA

e-mail: jhughes@anderson.ucla.edu

J. Liu

e-mail: jliu@anderson.ucla.edu

J. Liu

University of California San Diego, San Diego, CA, USA

e-mail: junliu@ucsd.edu
} 
future dividends. Our analysis attempts to fill a gap in the empirical literature on the efficacy of implied cost of capital as a proxy for expected return on equity. In particular, we examine the relation between the implied cost of capital and the expected returns when the latter are stochastic. Our results raise the possibility that some of the empirical results in the implied cost of capital literature may be an artifact of the difference between the two.

The assumption of constant expected returns can be challenged on both theoretical and empirical grounds. In his seminal study of inter-temporal capital asset pricing, Merton (1973) shows that variations in investors' investment opportunity set as a consequence of dependency on random states of nature induces stochastic expected returns. On the empirical side, Shiller (1981) contends that the U.S. stock market is too volatile to be explained by cash flow innovations from a stationary distribution, implying that the expected returns must also be time varying. Campbell (1991) shows that a large proportion of stock return variation is due to variation in expected returns. More recent empirical studies by Fama and French (1997); Jagannathan and Wang (1996) also conclude that expected returns are time varying.

In asset pricing theory, expected return of an asset is completely determined by its nondiversifiable risk, a property that may not be shared by implied cost of capital. Given stochastic expected returns, we show that implied cost of capital differs from expected return, and this difference is a function of leverage, growth in cash flows, expected return volatility, cash flow volatility, and the correlation between expected return news and cash flow news. The difference arises for two reasons. First, equity prices depend nonlinearly on the future expected returns; thus, there is an effect due to Jensen's inequality. Second, there is a correction due to the covariance between the future expected returns and the future cash flows. Our characterization of the difference generates a number of empirical implications, casting the existing findings in the literature in new light.

First, Claus and Thomas (2001), and subsequently Gebhardt et al. (2001); Easton et al. (2002) used the implied cost of capital to infer the magnitude of the market risk premium. Notably, they found that the "ex ante equity risk premium" inferred from the implied cost of capital measures is only about 3\%, far lower than the historical averages observed in the U.S. While they attribute the low estimate to a longitudinal decline in market risk premiums, our result that, on average, the implied cost of capital can be expected to be lower than the expected returns due to Jensen's inequality offers another explanation.

Second, studies by Gebhardt et al. (2001); Gode and Mohanram (2003) examined whether implied cost of capital measures capture previously unidentified priced risks in the cross section. In particular, they found that such measures are significantly correlated with firm characteristics such as growth, leverage, and idiosyncratic risk, after controlling for beta. While it is tempting to conclude that these analyses discovered priced risk factors not previously identified in the asset pricing literature, our results demonstrate that even if risk is entirely captured by factor betas in determining expected return, given stochastic expected returns, implied cost of capital is correlated with growth, leverage, and idiosyncratic risk after controlling for betas.

Third, along similar lines to the second group of studies, Guay et al. (2003); Easton and Monahan (2005) examine the efficacy of implied cost of capital 
measures as proxies for priced risks by investigating whether those measures have predictive power with respect to future stock returns. While their general result is insignificant for all implied cost of capital measures, they found improvement in significance when they controlled for analyst forecast inefficiency or firm growth. These findings can be potentially explained by our results. Because implied cost of capital differs from the expected returns by a function of growth, leverage, beta volatility, and cash flow volatility, omission of these correlated factors may cause the coefficient estimate on implied cost of capital to be biased. Explicit control of these variables, such as the control for growth in Easton and Monahan (2005), helps to alleviate this problem.

Fourth, implied cost of capital measures have been used as proxies for expected returns in addressing a variety of research questions pertaining to relations between cost of capital and characteristics of the firm's information environment. For example, Botosan (1997); Botosan and Plumlee (2002) found that corporate disclosure levels are negatively correlated with implied cost of capital, Hail and Leuz (2006) found that features of countries' legal institutions are significantly correlated with implied cost of capital, and Hribar and Jenkins (2004) found earnings restatements lead to a higher implied cost of capital. The results of our analysis suggest that correlations such as these could be artifacts of the difference between implied cost of capital and expected returns if growth in cash flows is correlated with the variables under investigation.

We emphasize that the purpose of our study is not to disparage prior literature. This literature has generated many useful insights not available from studies that use average returns as proxies for expected returns. Rather, the motivation is to establish a theoretical foundation that deepens understanding of the properties of implied cost of capital in a context of stochastic expected returns, a context well supported by recent evidence in finance and economics. Future research should consider our results in designing empirical tests and interpreting statistical results.

While the primary contribution of the paper lies in offering alternative theorybased interpretations of a growing body of empirical results, our analysis also extends earlier work on the valuation of debt and equity securities (for example, Vasicek 1977; Cox et al. 1985; Ang and Liu 2004; Miles and Ezzell 1980). The insight that bond yield, which is the implied cost of capital for bonds, may differ from the bond's expected returns on average has been long recognized in the fixed income literature (for example, Vasicek 1977; Cox et al. 1985). Our study generalizes this insight to equities. The fixed income literature does not need to model cash flows since they are constant. In contrast, because we examine equities, we adopt an analytical structure similar to Ang and Liu (2004), with assumptions of stochastic expected returns, stochastic cash flows, and allowing a correlation between the two. Given the stochastic aspect of cash flows and our later introduction of leverage in altering equity risk, the generalization to equities is not direct. ${ }^{1}$

\footnotetext{
1 We depart from Ang and Liu (2004) by adding structure that allows us to achieve a closed form characterization of the difference between average expected return and implied cost of capital, an issue outside the scope of their analysis.
} 
The rest of the paper is organized as follows: In the next section, we analyze the relation between average expected returns and the implied cost of capital. In Sect. 3, we discuss the empirical implications. We conclude in Sect. 4.

\section{Model}

\subsection{Discounted cash flow model under stochastic expected returns}

In this subsection, we develop the discount cash flow formula for equity valuation under stochastic expected returns. Our analysis is an extension of Ang and Liu (2004), who systematically examines how cash flows should be discounted under stochastic expected returns. As noted earlier, we depart from theirs by adopting more specific assumptions that allow for a closed form solution. This solution is essential in later analysis, when we examine the relation between implied cost of capital and expected returns.

The value of an asset at $t=0, A_{0}$, satisfies the inter-temporal relation:

$$
A_{0}=\mathrm{E}_{0}\left(\exp \left(-\mu_{0}\right)\left(\tilde{A}_{1}+\tilde{c}_{1}\right)\right) \text {, }
$$

where $\exp \left(\mu_{0}\right)$ is the expected (gross) return for the period between 0 and 1 known at the beginning of the period and $\tilde{c}_{1}$ is "free cash flow" to both debt and equity investors for that period. We use the exponential form of expected returns for mathematical simplicity. Iterating Eq. 1 one further period, we get

$$
\begin{aligned}
A_{0} & =\mathrm{E}_{0}\left(\exp \left(-\mu_{0}\right) \tilde{c}_{1}\right)+\mathrm{E}_{0}\left(\exp \left(-\mu_{0}-\mu_{1}\right) \mathrm{E}_{1}\left(\tilde{A}_{2}+\tilde{c}_{2}\right)\right) \\
& =\mathrm{E}_{0}\left(\exp \left(-\mu_{0}\right) \tilde{c}_{1}\right)+\mathrm{E}_{0}\left(\mathrm{E}_{1}\left(\exp \left(-\mu_{0}-\mu_{1}\right)\left(\tilde{A}_{2}+\tilde{c}_{2}\right)\right)\right) \\
& =\mathrm{E}_{0}\left(\exp \left(-\mu_{0}\right) \tilde{c}_{1}\right)+\mathrm{E}_{0}\left(\exp \left(-\mu_{0}-\mu_{1}\right)\left(\tilde{A}_{2}+\tilde{c}_{2}\right)\right) .
\end{aligned}
$$

The second equality holds because expected return is known at the beginning of each period, and the third equality holds because of the law of iterated expectations. Successively iterating the above expression to infinity, and assuming that the transversality condition, $\prod_{s=0}^{\infty} \exp \left(-\mu_{s}\right) \tilde{A}_{\infty}=0$, holds, we obtain the following discounted cash flow model under stochastic expected returns:

$$
A_{0}=\mathrm{E}_{0}\left(\sum_{t=0}^{\infty}\left(\prod_{s=0}^{t} \exp \left(-\mu_{s}\right)\right) \tilde{c}_{t+1}\right)=\sum_{t=0}^{\infty} \mathrm{E}_{0}\left(\exp \left(-\sum_{s=0}^{t} \mu_{s}\right) \tilde{c}_{t+1}\right) .
$$

As depicted above, discounting of future cash flows is achieved by taking the product of future (stochastic) expected returns $\prod_{s=0}^{t} \exp \left(-\mu_{s}\right)$. If expected returns are a constant, that is, $\tilde{\mu}_{t}=\bar{\mu}$, then $\prod_{s=0}^{t} \exp \left(-\mu_{s}\right)=\exp (-t \bar{\mu})$, and Eq. 2 is reduced to the conventional discounted cash flow model, that is, $A_{0}=\sum_{t=0}^{\infty} \mathrm{E}_{0}\left(\exp (-t \bar{\mu}) \tilde{c}_{t+1}\right)$.

To parameterize Eq. 2, we assume that the logarithms of expected returns, $\mu_{t}$, are determined by a factor structure. Without further loss of generality, we assume a one-factor model: 


$$
\tilde{\mu}_{t}=r_{f}+\lambda \tilde{\beta}_{t}
$$

where

$$
\tilde{\beta}_{t}=\bar{\beta}+\sigma_{\beta} \tilde{\varepsilon}_{\beta t},
$$

$r_{f}$ (the risk free rate), $\lambda$ (the factor risk premium), $\bar{\beta}$, and $\sigma_{\beta}$ are constants, and $\tilde{\varepsilon}_{\beta t}, t=0, \ldots, \infty$, are independent standard normal random variables. The realization of $\tilde{\beta}_{t}$ is observed at the beginning of each period, that is, $\beta_{1}$ is known at time 1 . Since the logarithms of expected returns are distributed normal, expected returns are bounded below at 0 ; hence, our assumption satisfies limited liability.

We point out that while stochastic expected returns can be achieved through the risk free rate, factor risk premiums, factor loadings, or a combination of the three, there is no loss of generality in considering the case where factor loadings (betas) are stochastic. The analysis is essentially the same if we instead make the other components of the expected return stochastic. ${ }^{2}$ This specification is consistent with the empirical findings of time dependent betas in Fama and French (1997) and is consistent with the conditional CAPM specification of Jagannathan and Wang (1996).

We further assume that future cash flows, $c_{t+1}$, are generated by

$$
\tilde{c}_{t+1}=c_{t} \exp \left(g+\sigma_{c}\left(\rho \tilde{\varepsilon}_{\beta t+1}+\sqrt{1-\rho^{2}} \tilde{\varepsilon}_{c t+1}\right)\right),
$$

where $g, \rho$, and $\sigma_{c}$ are constants and $\varepsilon_{c t+1}, t=0, \ldots, \infty$, are independent standard normal random variables. The cash flow specification in 5 allows contemporaneous correlation between log cash flows and log expected returns, with the correlation captured by $\rho$. However, since betas and, hence, expected returns are observed at the beginning of each period, conditioning on information at the beginning of period $t$, $\mu_{t}$ is known and thus does not co-vary with $\tilde{c}_{t+1}$. When the correlation coefficient $\rho$ is zero, the cash flows dynamics are reduced to that assumed in the Gordon growth model, that is, $\tilde{c}_{t+1}=c_{t} \exp \left(g+\sigma_{c} \tilde{\varepsilon}_{c t+1}\right)$.

We note that the stochastic nature of expected returns and cash flows are quite different in that the shocks to expected returns are temporary and the shocks to cash flows are permanent. This is reasonable because the time series of expected returns should be stationary, while firms and their cash flows are growing on average.

Since we assume that $\beta_{0}$ is known at $t=0$, it follows that

$$
\mathrm{E}_{0}\left(\exp \left(-\sum_{s=0}^{t} \mu_{s}\right) \tilde{c}_{t+1}\right)=\exp \left(-\mu_{0}\right) \mathrm{E}_{0}\left(\exp \left(-\sum_{s=1}^{t} \mu_{s}\right) \tilde{c}_{t+1}\right) .
$$

Substituting for cash flows from 5 and taking expectations, we obtain

$$
\mathrm{E}_{0}\left(\exp \left(-\sum_{s=0}^{t} \mu_{s}\right) \tilde{c}_{t+1}\right)=\exp \left(-\mu_{0}+g+\frac{1}{2} \sigma_{c}^{2}\right) \mathrm{E}_{0}\left(\exp \left(-\sum_{s=1}^{t} \mu_{s}\right) \tilde{c}_{t}\right) .
$$

Successive substitution for $\mu_{t}, t \in\{t-1,0\}$, leads to

\footnotetext{
2 The analysis will be less tractable if we allow both beta and the factor risk premium to be stochastic at the same time.
} 


$$
\begin{aligned}
\mathrm{E}_{0}\left(\exp \left(-\sum_{s=0}^{t} \mu_{s}\right) \tilde{c}_{t+1}\right)= & c_{0} \exp \left(-\mu_{0}+g+\frac{1}{2} \sigma_{c}^{2}-t\left(r_{f}+\lambda \bar{\beta}-g-\frac{1}{2}\left(\rho \sigma_{c}-\lambda \sigma_{\beta}\right)^{2}\right.\right. \\
& \left.\left.-\frac{1}{2}\left(\sqrt{1-\rho^{2}} \sigma_{c}\right)^{2}\right)\right)
\end{aligned}
$$

Thus, we have

$$
A_{0}=\sum_{t=0}^{\infty} c_{0} \exp \left(-\mu_{0}+g+\frac{1}{2} \sigma_{c}^{2}-t\left(r_{f}+\lambda \bar{\beta}-g-\frac{1}{2}\left(\rho \sigma_{c}-\lambda \sigma_{\beta}\right)^{2}-\frac{1}{2}\left(1-\rho^{2}\right) \sigma_{c}^{2}\right)\right) \text {. }
$$

Taking the infinite sum results in the following proposition about the firm's asset valuation:

Proposition 1 Given assumptions (1)-(5), the firm's asset value can be expressed as

$$
A_{0}=c_{0} \frac{\exp \left(g+\frac{1}{2} \sigma_{c}^{2}\right)}{\exp \left(\mu_{0}\right)\left(1-\exp \left(-\left(r_{f}+\lambda \bar{\beta}-g-\frac{1}{2}\left(\rho \sigma_{c}-\lambda \sigma_{\beta}\right)^{2}-\frac{1}{2}\left(1-\rho^{2}\right) \sigma_{c}^{2}\right)\right)\right)} .
$$

Under constant expected returns, $\tilde{\mu}_{t}=\bar{\mu}$ for all $t$, Proposition 1 is reduced to the familiar Gordon Growth model with uncertainty:

$$
A_{0}=\frac{\exp \left(g+\frac{1}{2} \sigma_{c}^{2}\right)}{\exp \left(\mu_{0}\right)-\exp \left(g+\frac{1}{2} \sigma_{c}^{2}\right)} c_{0}=\frac{c_{0}}{\exp \left(\mu_{0}-g-\frac{1}{2} \sigma_{c}^{2}\right)-1}
$$

\subsection{Relation between implied cost of capital and expected returns}

Prominent in recent accounting research is the implied cost of capital literature (for example, Botosan 1997; Claus and Thomas 2001, Gebhardt et al. 2001) that regards expected return as an internal rate of return derived from the discounted dividends formula (or equivalently its accounting transformations). However, this treatment is grounded in asset pricing models for which expected return is assumed to be constant. Taking implied cost of capital as an ex ante measure of expected percentage returns, these studies analyze how this measure speaks to firms' risk exposures or aggregate market risk premiums. In this section, we theoretically explore the average relation between implied cost of capital and expected returns and depict significant aspects in which they may differ when expected returns are assumed to be stochastic.

To begin, we formally define the implied cost of capital as the internal rate of return that equates the present value of cash flows with asset value: 


$$
A_{0}=\mathrm{E}_{0}\left(\sum_{t=0}^{\infty} \exp \left(-t \pi_{0}\right) \tilde{c}_{t+1}\right)
$$

where $\pi_{0}$ is the logarithm of implied cost of capital at time 0 . Because we are considering the valuation of assets by discounting future cash flows, the implied cost of capital can be considered as the weighted average cost of capital, or WACC, as defined in corporate finance textbooks.

Combining assumption (1) and (11) and applying similar calculations to those in the previous subsection, we obtain the following expression for firm's asset value as a function of the implied cost of capital:

$$
A_{0}=\frac{\exp \left(g+\frac{1}{2} \sigma_{c}^{2}\right)}{\exp \left(\pi_{0}\right)-\exp \left(g+\frac{1}{2} \sigma_{c}^{2}\right)} c_{0} .
$$

It immediately follows that under constant expected returns, $\tilde{\mu}_{t}=\bar{\mu}$ for all $t$, the fact that Eqs. 10 and 12 hold at the same time implies that expected return should be equal to implied cost of capital, that is, $\bar{\mu}=\pi_{t}$ for all $t$, a result demonstrated by Samuelson (1965). However, it is also clear that in the general case where expected returns are stochastic, the implied cost of capital has a more complex relation with expected returns.

To establish the relation in the general case, we equate the right hand sides of Eqs. 9 and 12 and obtain

$$
\begin{aligned}
\exp \left(\pi_{0}\right)= & \exp \left(\mu_{0}\right)-\exp \left(\mu_{0}-\left(r_{f}+\lambda \bar{\beta}-g-\frac{1}{2}\left(\rho \sigma_{c}-\lambda \sigma_{\beta}\right)^{2}-\frac{1}{2}\left(1-\rho^{2}\right) \sigma_{c}^{2}\right)\right) \\
& +\exp \left(g+\frac{1}{2} \sigma_{c}^{2}\right)
\end{aligned}
$$

In expression $13, \mu_{0}$ depends on the realization of the random variable $\tilde{\beta}_{t}$ at time 0 . To obtain an average relation between expected return and implied cost of capital, we step back and take the unconditional expectation of both sides of 11 , which leads to the following proposition:

Proposition 2 Given assumptions (1)-(5) and definition (11), the ex ante relation between implied cost of capital and expected return is

$$
E\left(\exp \left(\pi_{0}\right)-\exp \left(\mu_{0}\right)\right)=\left(1-\exp \left(\lambda \sigma_{\beta}\left(\lambda \sigma_{\beta}-\rho \sigma_{c}\right)\right)\right) \exp \left(g+\frac{1}{2} \sigma_{c}^{2}\right) .
$$

Therefore, under stochastic expected returns, on average, the implied cost of capital will be equal to expected return if and only if the technical condition $\lambda \sigma_{\beta}\left(\lambda \sigma_{\beta}-\rho \sigma_{c}\right)=0$ is satisfied. The Samuelson equivalence result under $\sigma_{\beta}=0$ is too strong since $\sigma_{\beta}=0$ is sufficient but not necessary. In the general case where this technical condition is violated, the average difference between expected returns and the implied cost of capital is a function of beta volatility, $\sigma_{\beta}$, cash flow volatility, $\sigma_{c}$, the correlation between expected returns and cash flows, $\rho$, and growth in cash flows, $g$. Because empirical studies tend to focus on cost of capital applicable for 
equity valuation rather than asset valuation as we have shown up to this point, in the next section, we extend the analysis to consider the effects of leverage.

\subsection{Effect of leverage}

For a levered firm, the expected return on equity, $e^{\mu_{E_{t}}}$, is implied by its relation to the expected return on assets, the risk free rate, and the leverage ratio:

$$
\exp \left(\mu_{t}\right)=\left(1-k_{t}\right) \exp \left(r_{f}\right)+k_{t} \exp \left(\mu_{E_{t}}\right),
$$

where $\mu_{E_{t}}$ is the logarithm of expected equity return and $k_{t}$ is the equity to asset ratio. Thus, the expected return on equity at $t=0$ is

$$
\exp \left(\mu_{E_{0}}\right)=\frac{1}{k_{0}}\left[\exp \left(\mu_{0}\right)-\left(1-k_{0}\right) \exp \left(r_{f}\right)\right]
$$

We can similarly define the implied cost of equity, $\pi_{E_{0}}$, as the implied cost of asset adjusted for leverage:

$$
\exp \left(\pi_{E_{0}}\right)=\frac{1}{k_{0}}\left[\exp \left(\pi_{0}\right)-\left(1-k_{0}\right) \exp \left(r_{f}\right)\right]
$$

Substituting from Eqs. 16 and 17 into Eq. 14, we obtain a relation between implied cost of equity and the expected return on equity:

$$
E\left(\exp \left(\pi_{E 0}\right)-\exp \left(\mu_{E 0}\right)\right)=\frac{1}{k}\left(1-\exp \left(\lambda \sigma_{\beta}\left(\lambda \sigma_{\beta}-\rho \sigma_{c}\right)\right)\right) \exp \left(g+\frac{1}{2} \sigma_{c}^{2}\right)
$$

where $k=\frac{1}{E\left(1 / k_{0}\right)}$. Thus, just as leverage magnifies the risk of investments, it also magnifies the difference between expected returns and implied cost of capital.

Note that the implied cost of equity is defined as the implied cost of assets magnified by leverage; it is not in general the discount rate that equates equity value with the present value of expected future dividends, that is,

$$
A_{0} \neq D T_{0}+\mathrm{E}_{0}\left(\sum_{t=0}^{\infty} \exp \left(-t \pi_{E_{0}}\right) \tilde{D}_{t+1}\right)
$$

where $D T_{0}$ is the value of debt at time $0, \tilde{D}_{t+1}, t=0,1,2 \ldots$, are the future dividends. This is obviously the case if we let expected return on assets to be a constant but let the leverage ratio fluctuate over time. However, a sufficient condition for the equality to hold is that both the expected return on assets and the leverage ratio remain constants over time, an insight first derived by Miles and Ezzell (1980).

From an empirical standpoint, it is reasonable to assume that

$$
A_{0} \approx D T_{0}+\mathrm{E}_{0}\left(\sum_{t=0}^{\infty} \exp \left(-t \pi_{E_{0}}\right) \tilde{D}_{t+1}\right) \text {. }
$$

To consider leverage, we have at least two choices. One approach is to first model an unlevered firm and then add leverage as we have done through Eq. 18. Another approach is to directly consider the expected returns for equity and cash 
flows to equity investors, replacing asset beta with equity beta and free cash flows with dividends. Because leverage magnifies the volatility in both expected returns on equity and future dividends, it will in turn magnify the average difference between expected returns and the implied cost of equity capital (Proposition 2), a result qualitatively similar to Eq. 18 .

\section{Empirical implications}

The above analysis generates a number of empirical implications. First, in the implied cost of capital literature estimates of the ex ante market risk premium run about 3\% (for example, Claus and Thomas 2001; Gebhardt et al. 2001; Easton et al. 2002), much lower than estimates based on historical average returns, which are between $6 \%$ and $8 \%$ depending on the time period and the method of calculation (See, for example, Ibbotson Associates Yearbook 2005). An explanation offered for the discrepancy is that market risk premium is declining, or that the long run average of US equity returns is biased too high because the U.S. has been fortunate in the last century.

Our analysis suggests an additional explanation. Equation 18 states that, under stochastic expected returns, on average, expected returns and implied cost of capital will be equal if and only if $\lambda \sigma_{\beta}\left(\lambda \sigma_{\beta}-\rho \sigma_{c}\right)=0$; that is, expected returns will be greater (less) than implied cost of capital depending on whether $\lambda \sigma_{\beta}\left(\lambda \sigma_{\beta}-\rho \sigma_{c}\right)$ is greater (less) than zero. While precise calculation of $\lambda \sigma_{\beta}\left(\lambda \sigma_{\beta}-\rho \sigma_{c}\right)$ involves empirical measures of all four variables, there is evidence to infer that the sign is positive. This is because $\lambda, \sigma_{\beta}$, and $\sigma_{c}$ are all positive and Campbell (1991); Campbell and Ammer (1993) found that at the market level the correlation between cash flow news and expected return news are weakly negative. Accordingly, our results suggest that estimates of ex ante risk premiums inferred from implied cost of capital should be lower than those inferred from historical average returns.

To calibrate the magnitude of this difference numerically, we sought plausible estimates of the parameters contained in Eq. 18. As mentioned in the model setup, although our analysis assumes that time variation in expected returns comes solely from the time variation in beta, we made this choice for purely expositional reasons. In reality, the time variation in expected returns could also come from the time variation in risk free rates and market risk premiums. Of course, at the market level, beta is one, so the volatility in expected returns is driven by the volatility of risk free rates and market risk premiums. ${ }^{3}$ Because the correlation between cash flow news and expected return news is small, the value of Eq. 18 is most sensitive to the volatility in expected returns. If we set $\sigma_{c}=15, g=5, \rho=-10$, then the difference will be $1.2 \%, 2 \%$, and $3 \%$ for standard deviations of expected returns of $10 \%, 13 \%$ and $16 \%$, respectively. While, historically, realized standard deviation of market returns can reach as high as $20 \%$, only a part is due to the volatility in expected returns. If half the variance in market returns is due to the variation in

\footnotetext{
${ }^{3}$ For simplicity, rather than first consider unlevered parameter values and then add leverage, here we directly consider leverage through leveraged parameter values.
} 
expected returns, then the standard deviation of expected returns should be close to $14 \%$, which translates into a $2.3 \%$ average difference between expected returns and implied cost of capital. Campbell (1991) estimates that more than half of the stock volatility at the market level is due to the volatility in expected returns, but he also cautions that the estimates are not precise. We therefore conclude that the difference between implied cost of capital and expected returns is likely to be a significant factor in explaining the empirical results in the literature, but it is unlikely to be the only explanation.

Our results are likely to be more pronounced in the cross-section, because in addition to the variability in the market risk premium, the variability in beta estimates also contributes to the difference between the expected returns and the implied cost of capital. Prior research such as Gebhardt et al. (2001); Gode and Mohanram (2003) examined whether the implied cost of capital correlates with various measures other than proxies for previously identified systematic risk factors in cross-section. They found that, after controlling for firm beta, implied cost of capital is significantly correlated with leverage, measures of idiosyncratic risk, and growth forecasts. These findings do not reconcile with neoclassical asset pricing theories. Either the Capital Asset Pricing Model or Arbitrage Pricing Theory dictates that idiosyncratic risk should not be priced. Moreover, leverage should only affect expected returns through beta. Hence, controlling for beta, leverage should no longer be significant in determining expected returns. In theory, it is not clear how growth in earnings and cash flows should enter the determination of expected returns. To the extent that higher growth firms are more risky, the risk should be captured in higher betas and, having controlled for beta, growth should not affect expected returns.

Rather than abandoning extant theory in thinking about the pricing implications of idiosyncratic risks, leverage, and growth, our analysis suggests an alternative explanation for the empirical findings. Even though expected return $\exp \left(\mu_{E_{0}}\right)$ is determined purely by firm beta and the market risk premium, after controlling for beta, Eq. 18 makes it evident that implied cost of capital can be correlated with leverage $(k)$, idiosyncratic risk $\left(\sigma_{c}\right)$, and growth $(g)$. This can be seen clearly if we rewrite Eq. 20 in a regression form:

$$
\exp \left(\pi_{E_{0}}\right)=\exp \left(\mu_{E_{0}}\right)+\frac{1}{1-k}\left(1-\exp \left(\lambda \sigma_{\beta}\left(\lambda \sigma_{\beta}-\rho \sigma_{c}\right)\right)\right) \exp \left(g+\frac{1}{2} \sigma_{c}^{2}\right)+\varepsilon,
$$

where $\varepsilon$ is the regression residual (the time and firm subscripts are omitted).

As noted earlier, the quantity $\lambda \sigma_{\beta}\left(\lambda \sigma_{\beta}-\rho \sigma_{c}\right)$ determines the sign of the difference between expected return and the implied cost of capital. While we have inferred that it is positive at the market level, we expect it become negative in crosssection. This is because prior research on variance decomposition of stock returns finds vastly different results at the market and firm levels. At the market level, Campbell (1991); Campbell and Ammer (1993) find that (a) stock volatility is primarily driven by volatility in expected returns, rather than volatility in cash flows, and (b) the correlation between cash flow news and expected return news is 
zero to slightly negative. At the firm level, Vuolteenaho (2002) finds the opposite results. Stock volatility is dominated by volatility in cash flow news, and the correlation between cash flow news and expected return news is highly positive. Therefore, in cross-sectional regressions, we expect the coefficient on the second term on the right hand side of Eq. 19 to be positive, which is consistent with empirical evidence.

Differences in predictions of earnings growth at the market and firm levels across empirical studies further suggest that empirical estimates of ex ante market risk premiums will differ depending on whether one conducts market level analysis or firm level analysis. Given the same assumptions for earnings growth, one should find that the market risk premium estimates will be lower under market level analysis than under firm level analysis. We are not aware of any study that employs the same assumptions but compares results estimated at the market level and in the cross-section.

Our analysis also has implications for studies that investigate the efficacy of the implied cost of capital measures by checking whether these measures can help to predict future returns. Guay et al. (2003) found no evidence that the implied cost of capital measures can predict future stock returns. They attribute the finding partly to the inefficiency of analyst earnings forecasts. The general null result is confirmed by Easton and Monahan (2005), who further found that the implied cost of capital measures are correlated with future returns if the earnings growth forecast is low. To see how our analysis speaks to these empirical results, we rearrange Eq. 22 while recognizing that realized stock returns equal the expected returns plus noise:

$$
r_{1}=\exp \left(\pi_{E_{0}}\right)-\frac{1}{1-k}\left(1-\exp \left(\lambda \sigma_{\beta}\left(\lambda \sigma_{\beta}-\rho \sigma_{c}\right)\right)\right) \exp \left(g+\frac{1}{2} \sigma_{c}^{2}\right)+\eta
$$

where $r_{1}$ is next period realized stock return and $\eta$ is the regression residual. Equation 20 predicts a coefficient of one on the implied cost of equity capital, provided that one controls for leverage, growth, idiosyncratic risk, and the volatility of the expected returns. However, the estimated coefficient will be biased if controls for these variables are omitted since, as we have demonstrated, these variables are correlated with the difference between implied cost of capital and expected returns.

The Easton and Monahan (2005) finding that the implied cost of capital becomes more significantly correlated with future returns when the expected growth rate is low is consistent with our result that the difference between expected returns and the discount rate is negatively correlated with the expected growth rate. Along similar lines, our analysis further suggests that the strength of the correlation will be higher if the firm's beta displays less time series variation, or if the firm has lower leverage, since in both cases the difference between the expected returns and the implied cost of capital is small.

Finally, our analysis suggests that empirical studies that employ implied cost of capital as a proxy for expected return in examining the pricing implications of the firms' information environment should guard against spurious correlation. While a significant correlation between the implied cost of capital and a test variable can be due to a significant correlation between expected return and the test variable, it can 
also be due to a correlation between the test variable and omitted controls for leverage, growth, and beta and cash flow volatility. For example, Botosan (1997); Botosan and Plumlee (2002) examine the correlation between implied cost of capital and firm's disclosure score as reported by financial analysts and find a positive relation. Though these studies control for conventional risk proxies such as beta, book-to-market ratio and size, they do not control for the factors that contribute the difference between implied cost of capital and expected return. To the extent that the firm's disclosure policy is correlated with growth as documented by Lang and Lundholm (1996), the correlation between implied cost of capital and the disclosure score could be confounded by the correlation between growth and disclosure scores.

\section{Conclusion}

While much of the modern financial research focuses on the expected return, it is notoriously difficult to measure. The traditional approach of using average returns to proxy for expected return has serious problems because of the large influence exerted by significant information events (for example, Elton 1999). The employment of implied cost of capital as an alternative proxy is a highly useful innovation that may generate insights not available to conventional asset pricing tests. However, as demonstrated in this paper, the implied cost of capital also contains noises and biases that can potentially contaminate the test results.

Assuming stochastic expected returns, we have shown that the implied cost of equity capital is not equal to the expected return and is a function of expected return on equity, leverage, growth, beta volatility, and cash flow volatility. The dependence of implied cost of equity capital on leverage, growth, beta volatility, and cash flow volatility arises from the Jensen's inequality because price is a nonlinear function of the (stochastic) expected returns. When expected returns are a constant, these variables drop out of the relation between implied cost of capital and expected returns, and we are back to Samuelson's (1965) classical equivalence result.

Our analysis suggests that, even if expected returns are purely determined by a factor model and beta risk is the only risk that is priced, one might observe results such as those documented in empirical studies due to the result that under stochastic expected returns the implied cost of capital and expected returns are, on average, not equivalent. Examples of such results include estimates of equity risk premiums substantially below historical averages (for example, Claus and Thomas 2001; Gebhardt et al. 2001), relations between implied cost of capital to measures of leverage, growth, and variables associated with firm-specific risks (for example, Gebhardt et al. 2001; Gode and Mohanram 2003), weak associations between implied cost of capital and future returns conditional on growth (for example, Guay et al. 2003; Easton and Monahan 2005), and associations between implied cost of capital and disclosure policies (for example, Botosan 1997; Botosan and Plumlee 2002).

At a conceptual level, the measurement issues in implied cost of capital should be anticipated because the vast literature in finance, economics, and accounting has demonstrated that expected return is very difficult to measure. One cannot expect the implied cost of capital to resolve all measurement issues. Given that all proxies 
for expected return are noisy, we believe implied cost of capital is a highly useful tool and should be exploited in the studies of capital markets. However, when employing implied cost of capital as a proxy for expected return, one should be aware of and control for the differences identified in this study. In addition, it may make sense to revisit past studies to assess whether the results are robust after controlling for the differences between the implied cost of capital and expected returns.

Acknowledgments Special thanks are due to Jim Ohlson for helpful discussions and insights. We also received useful comments from Anil Arya, Ruihao Ke, Jake Thomas, Joel Demski, Rick Lambert, Carolyn Levine, Philip Stocken and seminar participants at Carnegie Mellon, HKUST, Yale, the 2008 AAA annual meetings and the 2008 RAST conference. All errors are our own.

Open Access This article is distributed under the terms of the Creative Commons Attribution Noncommercial License which permits any noncommercial use, distribution, and reproduction in any medium, provided the original author(s) and source are credited.

\section{References}

Ang, A., \& Liu, J. (2004). How to discount cash flows with time-varying expected returns. Journal of Finance, $\operatorname{LIX}(6), 2745-2783$.

Botosan, C. (1997). Disclosure level and the cost of equity capital. The Accounting Review, 72, 323-350.

Botosan, C., \& Plumlee, M. (2002). A re-examination of disclosure level and the expected cost of equity capital. Journal of Accounting Research, 40, 21-40.

Campbell, J. (1991). A variance decomposition for stock return. The Economic Journal, 101, 157-179.

Campbell, J., \& Ammer, J. (1993). What moves the stock and bond markets? A variance decomposition for long-term asset returns. Journal of Finance, 48, 3-37.

Claus, J., \& Thomas, J. (2001). Equity premia as low as three percent? Evidence from analysts' earnings forecasts for domestic and international stock markets. Journal of Finance, 56, 1629-1666.

Cox, J., Ingersoll, J., \& Ross, S. (1985). A theory of the term structure of interest rates. Econometrica, 53, 385-408.

Easton, P., \& Monahan, S. (2005). An evaluation of accounting-based measures of expected returns. The Accounting Review, 80, 501-538.

Easton, P., Taylor, G., Shroff, P., \& Sougiannis, T. (2002). Using forecasts of earnings to simultaneously estimate growth and the rate of return on equity investment. Journal of Accounting Research, 40, $657-676$.

Elton, E. (1999). Expected return, realized return and asset pricing tests. Journal of Finance, 40, 11991220.

Fama, E., \& French, K. (1997). Industry costs of equity. Journal of Financial Economics, 43, $153-193$.

Gebhardt, W., Lee, C., \& Swaminathan, B. (2001). Toward an implied cost of capital. Journal of Accounting Research, 39, 135-176.

Gode, D., \& Mohanram, P. (2003). Inferring the cost of capital using the Ohlson-Juettner model. Review of Accounting Studies, 8, 399-431.

Guay,W., Kothari, S., \& Shu, S. (2003). Properties of implied cost of capital using analysts' forecasts. Working paper, Rochester: University of Rochester.

Hail, L., \& Leuz, C. (2006). International differences in the cost of equity capital: Do legal institutions and securities regulation matter? Journal of Accounting Research, 44, 485-531.

Hribar, P., \& Jenkins, P. (2004). The effect of accounting restatements on earnings revisions and the estimated cost of capital. Review of Accounting Studies, 9, 337-356.

Jagannathan, R., \& Wang, Z. (1996). The conditional CAPM and the cross-section of expected returns. Journal of Finance, 51, 3-53.

Lang, M., \& Lundholm, R. (1996). Corporate disclosure policy and analyst behavior. The Accounting Review, 71, 467-492. 
Merton, R. (1973). An intertemporal capital asset pricing model. Econometrica, 41, 867-887.

Miles, J., \& Ezzell, J. (1980). The weighted average cost of capital, perfect capital markets, and project life: A clarification. Journal of Financial and Quantitative Analysis, 15, 719-730.

Samuelson, P. (1965). Proof that properly anticipated prices fluctuate randomly. Industrial Management Review, 6, 41-49.

Shiller, R. (1981). Do stock prices move too much to be justified by subsequent changes in dividends? The American Economic Review, 71, 421-436.

Vasicek, O. (1977). An equilibrium characterization of the term structure. Journal of Financial Economics, 5, 177-188.

Vuolteenaho, T. (2002). What drives firm-level stock returns? Journal of Finance, 57, 233-264. 